\title{
PERFORMANCE OF RIGIDLY INTERCONNECTED MULTIPLE FLOATING PONTOONS
}

\author{
Shafiuddin Amer Syed ${ }^{1}$ and J.S. Mani \\ ${ }^{1}$ Graduate Student, Department of Ocean Engineering, Indian Institute of Technology Madras, Chennai- 60036, \\ India.Ph. 0091-44-22575621, Fax: 0091-44-22578622,Email: amer@iitm.ac.in, syedsamer@yahoo.com \\ ${ }^{2}$ Professor, Department of Ocean Engineering, Indian Institute of Technology Madras, Chennai- 60036, India. Ph. \\ 091-44-22578634 Fax: 0091-44-22578622, Email: manijs@hotmail.com
}

\begin{abstract}
A floating system consisting of three pontoons equispaced, rigidly interconnected and taut moored to act as a single unit is analyzed. The theoretical formulation of the problem is based on the assumptions of irrotational fluid flow, an inviscid fluid, and small incident waves. The breakwater is assumed to be long and uniform in the direction parallel to the incident wave crests. The diffracted and the scattered potentials are obtained from the solution of boundary value problem using Green's identity method. The potentials and hence the free surface oscillations in between the spacing are also determined. The results of parametric study of varying space and drafts of the pontoons have been presented as a function of relative width of breakwater (Ratio of width of the breakwater to the wavelength). It is evident from the results that the spaces between the pontoons have a definite effect on transmission and reflection characteristics of a floating breakwater system. As the draft of the floating breakwater increases the bandwidth of incident wave frequencies for which $K_{t}$ (Ratio of transmitted wave height to incident wave height) is less than 0.2, also increases, thus ensuring a wider spectrum of operation. In addition the paper discusses on forces, oscillations in the interspaces and reflection coefficient.
\end{abstract}

Keywords: breakwater, pontoon, taut moored, free surface oscillations.

\section{NOMENCLATURE:}

d draft of the pontoon

$\mathrm{F}_{\mathrm{m}} \quad$ Force in the mooring line

$\mathrm{G} \quad$ Clear spacing between the pontoons

h Water depth

$\mathrm{H}_{\mathrm{i}} \quad$ Incident wave height

$\mathrm{g}^{*} \quad$ Special part of Green's function

$\mathrm{G}^{*} \quad$ Green's function expressed as a

function of space and time

$\mathrm{K}_{\mathrm{t}} \quad$ Transmission coefficient

$\mathrm{K}_{\mathrm{r}} \quad$ Reflection coefficient

L Wavelength

n Vector normal to incident surface

$\mathrm{n}_{\mathrm{i}} \quad$ Generalized directional cosines

$\mathrm{N} \quad$ Number of facets or sub divisions along the body boundary $\mathrm{S}_{\mathrm{o}}$

Re Real part of a complex quantity

$r \quad$ Radial direction

S Surface enclosing the flow domain $\Omega$

$(\xi, \eta)$ Source point

$S_{\varepsilon} \quad$ Surface enclosing $(\xi, \eta)$
$\mathrm{T} \quad$ Wave period

$\mathrm{W}_{\mathrm{p}} \quad$ Width of the individual pontoon

W Total width of the breakwater

$\nabla \quad$ Vector gradient operator

$\hat{\phi} \quad$ Velocity potential as a function of space and time

$\phi \quad$ Velocity potential as a function of space alone

$\phi_{o} \quad$ Incident velocity potential

$\phi_{S} \quad$ Scattered velocity potential

$\phi_{r} \quad$ Radiated velocity potential

$\phi_{T} \quad$ Total velocity potential

$\Omega \quad$ Flow domain

$\eta \quad$ Free surface elevation

$\omega \quad$ Angular frequency

$i$ unit complex value; $i=(0,1)$ in Argand's space 


\section{Introduction:}

Floating systems are in use in almost all seas, either it may be floating production platforms in deep waters or it may be floating docks in shallow waters. Floating breakwater is one such system, which is mainly used as wave attenuator at minor harbors and to some extent minor ports where the tranquility requirement is low and also at the places where the marine soil characteristics do not permit the installation of submerged, berm or any other type of breakwater which require a good foundation. Due to these reasons floating breakwater has been an important area of coastal and harbor research right from the past. Several configurations have been reported, tested and deployed by a number of researchers over the years. One of the earliest reports on the floating breakwater was by Joly (1905). The subject gained a momentum during the Second World War. The study of floating breakwater has gained a military importance as it is quicker way to deploy one to get a calm sea on leeside (Bretz, 1988). The use of a Bombardon type of floating breakwater during Normandy invasion to provide instant harbors to the invasion forces is the most famous example. On the other hand the floating breakwater was also reported for recreational harbors and small marinas and craft harbors (Richey and Nece, 1974). Several designs of breakwaters have been proposed, and tested over the years (Harris and Thomas, 1974; Kowalski, 1974). The type of structures mainly includes pontoons, long booms, tire mats, catamaran pontoons and other. The complexity of the structure is increased for a better performance. It was shown that for linked floating structures the hydrodynamic interactions between two bodies cannot be neglected (Fang and Kim, 1986). The motion response of linked floating breakwaters moored to the ocean floor was modeled mathematically by Valioulis (1989) to serve as an engineering tool in the design of breakwaters which involves the interaction of floating bodies. Drimer et al (1992) studied the performance of box type of breakwater and presented analytical solution of two dimensional linearised hydrodynamic problem. Shashikala et al (1997) studied the dynamic behavior of barge moored to a single point is dealt based on a finite element method. The effect of flexibility of the mooring line and the point of mooring on the response of the barge as well as the mooring line tension was investigated.

Williams and Abul -Azm (1997) investigated the performance of a dual pontoon-floating breakwater consisting of a pair of cylinders of rectangular cross section, connected by a rigid deck and was partly restrained by mooring fore and aft. It was reported that the wave reflection properties of the structure depend strongly on the width, draft and spacing of the pontoons and the mooring stiffness, while the excess buoyancy of the system is of lesser importance. Williams and Abul-Azm (2000) investigated the performance of long floating breakwater of rectangular cross section theoretically. It was proved that the breakwater characteristics depend strongly on width. Abul-Azm and Gesraha (2000) reported the characteristics of long rigid floating pontoon interacting with linear oblique waves in water of finite arbitrary depth by theoretical investigation. The authors concluded that the floating pontoon breakwater proved to be convenient alternative for the protection from waves in shallow water. Perunovic and Jensen (2003) studied the effect of shallow water on vertical wave induced loads acting on the hull of a ship, using modified linear frequency domain deep water strip theory. It was concluded that for ships moving in restricted water depths less than five times the draught the influence of water depth should be accounted for in design calculation. Drobyshevski (2004) presented analytical formulae for the fast computation of Hydrodynamic computations of rectangular structure in shallow waters. The radiation problem was solved using asymptotic expansions under the assumption of linear wave theory, by matching two 'outer' flows with the 'inner' flow near the structure edge. Liang et al (2004) studied the transmission and reflection characteristics and mooring tension introduced by a spar buoy floating breakwater. It was reported that the spar buoy floating breakwater is an effective wave attenuating structure.

As the performance of the breakwater is sensitive to the W/L (Ratio of width of breakwater to the incident wavelength) the floating pontoon demands a larger width for a better performance. Hence spaced pontoons are adopted in this study so as to save the material warranted by longer width. An investigation is carried out for a varied draft so as to simulate a site condition with a large tidal variation. In the process the effect of draft and width on the performance of the floating breakwater is explained. The present work highlights the effect of inter space between the rigidly linked taut moored pontoons in series acting as a floating breakwater. A boundary integral equation method is used to evaluate the performance of he structure numerically using the Green's identity method. Experimental studies are carried out for the optimum configuration obtained by the theoretical investigation. Performance of floating breakwater is evaluated in terms of its transmission and reflection 
characteristics. In addition the paper highlights the wave forces and the free surface oscillations in the interspaces of floating breakwater.

\section{Description of the Model:}

The floating breakwater model (Fig. 1) consists of three pontoons each of width $\mathrm{W}_{\mathrm{p}}$, separated by a clear spacing G, rigidly interconnected and taut moored to the ocean floor.

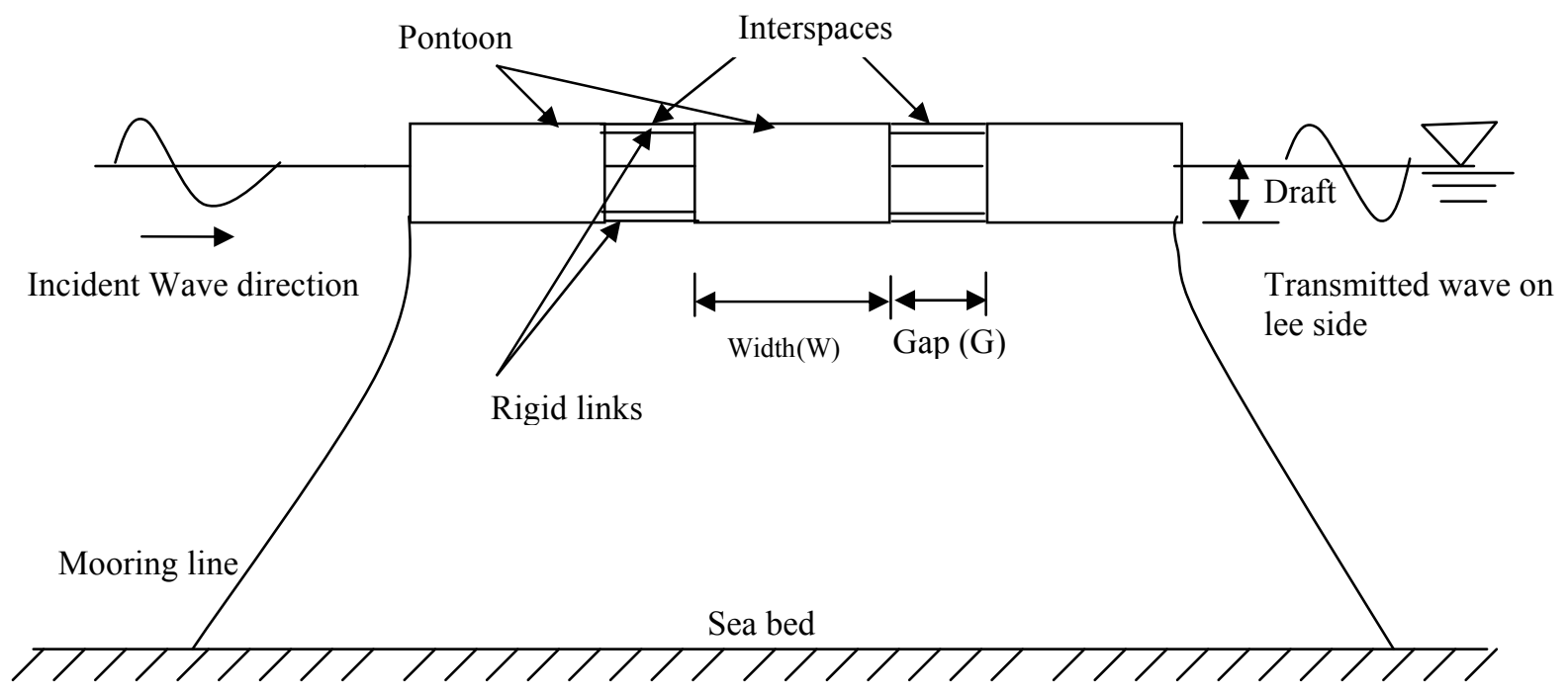

Fig. 1: Schematic diagram of rigidly interconnected floating pontoons taut moored to the Seabed

The draft of the structure is $\mathrm{d}$ and the water depth is $\mathrm{h}$. The whole unit acts as a single entity. The total width of the breakwater is $\mathrm{W}$ and is given as $\mathrm{W}=(2 \mathrm{G})+\left(3 \mathrm{~W}_{\mathrm{p}}\right)$

As the analysis is two dimensional, the length of the pontoons in third direction is not taken into account. The system is considered to be taut moored to the ocean bed.

\section{Methodology of Theoretical Study:}

Almost all the theoretical investigations to solve the wave-body interaction problems are based on the linear diffraction theory. The theory assumes an ideal fluid and an irrotational flow field, so that a velocity potential ' $\hat{\phi}$ exists. The velocity potential obeys Laplace's equation and a set of linearised boundary conditions on free surface, seabed and lateral boundaries. The governing equations and the boundary conditions adopted in general are as follows,

Governing equation:

$$
\nabla^{2} \hat{\phi}(x, y, z, t)=0
$$

Free surface condition

$$
\frac{1}{\mathrm{~g}} \frac{\partial^{2} \hat{\phi}}{\partial \mathrm{t}^{2}}+\frac{\partial \hat{\phi}}{\partial \mathrm{y}}=0
$$

Bottom condition

$$
\frac{\partial \hat{\phi}}{\partial y}=0
$$

Radiation boundary condition (Sommerfield's condition)

$$
\frac{\partial \hat{\phi}}{\partial|\mathrm{x}|} \mp \mathrm{ik} \hat{\phi}=\left.0\right|_{\mathrm{x}= \pm \infty}
$$


Wehausen and Laitone (1960) considered the above problem and derived the following form of the Green's functions using the complex variables. The Green's function for a two dimensional pulsating horizontal line source is given below

$$
\mathrm{G}^{*}(\mathrm{x}, \mathrm{y} ; \xi, \eta ; \mathrm{t})=\mathrm{g} *(\mathrm{x}, \mathrm{y} ; \xi, \eta) \mathrm{e}^{-\mathrm{i} \omega \mathrm{t}}
$$

The spatial part $\mathrm{g}(\mathrm{x}, \mathrm{y} ; \xi, \eta)$ is written as,

where,

$$
\mathrm{g} *(\mathrm{x}, \mathrm{y} ; \xi, \eta)=\mathrm{g}_{1}(\mathrm{x}, \mathrm{y} ; \xi, \eta)+\mathrm{ig}_{2}(\mathrm{x}, \mathrm{y} ; \xi, \eta)
$$

$$
\begin{aligned}
& g_{1}=\frac{1}{2 \pi} \log \left(\frac{r r_{2}}{h^{2}}\right)-\frac{1}{\pi} \int_{0}^{\infty}\left(\frac{k+v}{k} \frac{e^{-k h} \cosh k(h+y) \cosh k(h+\eta) \cos k(x-\xi)}{k \sinh k h-v \cosh k h}+\frac{e^{-k h}}{k}\right) d k \\
& \mathrm{~g}_{0}=\frac{v}{\mathrm{k}} \frac{\cosh \mathrm{k}(\mathrm{h}+\mathrm{y}) \cosh \mathrm{k}(\mathrm{h}+\eta)}{v \mathrm{~h}+\sinh ^{2} \mathrm{kh}}
\end{aligned}
$$

where,

$(\mathrm{x}, \mathrm{y})$ - point where the function $\mathrm{g} *$ is evaluated

$(\xi, \eta)$ - point where $\mathrm{g}^{*}$ is placed

$$
\begin{aligned}
& r=\sqrt{(x-\xi)^{2}+(y-\eta)^{2}} \\
& r_{2}=\sqrt{(x-\xi)^{2}+(y+\eta+2 h)^{2}}
\end{aligned}
$$

$\mathrm{k} \tanh \mathrm{kh}-v=0 ; v=\omega^{2} / \mathrm{g}$

$\mathrm{m}_{\mathrm{i}} ; \mathrm{i} \geq 1$ are positive real roots of the equation

$m \tan (m h)+v=0$.

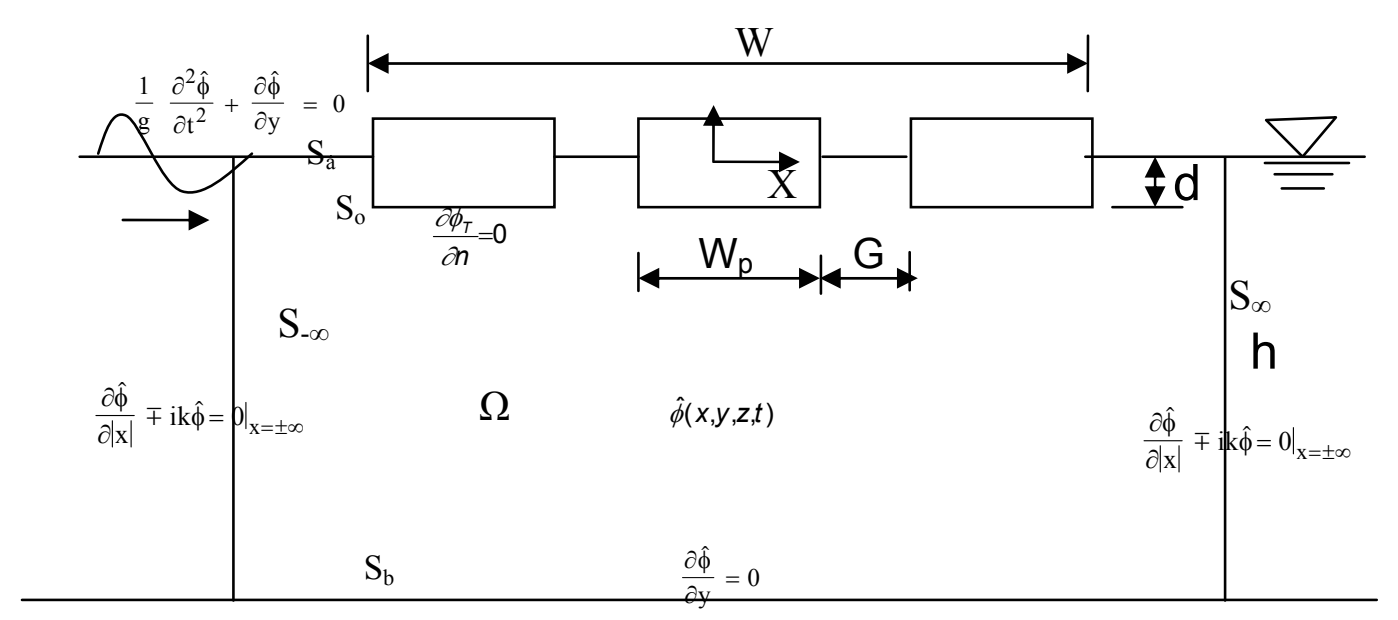

Fig. 2: Computational domain for theoretical study

The problem of determining an unknown potential function, over the flow domain $\Omega$ and the boundary curve ' $S$ ' enclosing it is set in the form of integral equations involving the potentials on the boundary curve 'S' alone using the green's identity. Referring to Fig.2, to evaluate a potential ' $\phi$ ' at any point $(\xi, \eta)$ inside the flow field, the identity is applied to $\phi$ and a singular function ' $\mathrm{g} *$ ' after placing the singularity at $(\xi, \eta)$. Where, ' $\mathrm{g}^{* \prime}$ is a singular function satisfying the Laplace equation everywhere except at $(\xi, \eta)$. The singular function selected for this purpose is a green's function which satisfies the free surface condition (Eq.2), bottom condition (Eq.3) and the 
Sommerfeld radiation condition (Eq.4) in addition to satisfying the field equation. The singular point $(\xi, \eta)$ is excluded from ' $\Omega$ ' by the ' $\mathrm{S}_{\varepsilon}$ ' to apply the green's identity.

The application of the Green's identity to ' $\phi$ ' and ' $\mathrm{g} *$ ' yields,

$$
\begin{aligned}
& \iint_{\Omega}\left[g^{*}(x, y ; \xi, \eta) \nabla^{2} \phi(x, y)-\phi(x, y) \nabla^{2} g^{*}(x, y ; \xi, \eta)\right] d \Omega= \\
& \int_{\mathrm{S}}\left[\mathrm{g} *(\mathrm{x}, \mathrm{y} ; \xi, \eta) \frac{\partial \phi(\mathrm{x}, \mathrm{y})}{\partial \underline{\mathrm{n}}}-\phi(\mathrm{x}, \mathrm{y}) \frac{\partial \mathrm{g} *(\mathrm{x}, \mathrm{y} ; \xi, \eta)}{\partial \underline{\mathrm{n}}}\right] \mathrm{ds}+ \\
& \int_{\mathrm{S} \varepsilon}\left[\mathrm{g} *(\mathrm{x}, \mathrm{y} ; \xi, \eta) \frac{\partial \phi(\xi, \eta)}{\partial \mathrm{r}}-\phi(\xi, \eta) \frac{\partial \mathrm{g} *(\mathrm{x}, \mathrm{y} ; \xi, \eta)}{\partial \mathrm{r}}\right] \mathrm{dS}_{\varepsilon}
\end{aligned}
$$

where,

$\mathrm{g}^{*}(\mathrm{x}, \mathrm{y} ; \xi, \eta)-\quad$ the spacial part of the Green's function satisfying the field equation and singular at $(\xi, \eta)$

n $\quad-\quad$ normal vector to the surface 'S'.

$\mathrm{r} \quad-\quad$ radial direction to point $(\xi, \eta)$

$\mathrm{S}_{\varepsilon} \quad-\quad$ surface enclosing $(\xi, \eta)$

For evaluation, the integral equation (Eq.12) is examined term wise. It can be seen that, the integrands on the left hand side of the above equation identically vanish because, both ' $\phi$ ' and ' $\mathrm{g}$ *' satisfy the Laplace's equation in $\Omega$. The integrands of the first part on the right hand side also vanish on, $\mathrm{S}_{\mathrm{a}}, \mathrm{S}_{+}, \mathrm{S}_{\mathrm{b}}$, and $\mathrm{S}_{-} \propto$ because of the fact that both ' $\phi$ ' and 'g*' satisfy the same boundary conditions on there curves. Evaluation of the second term on the right hand side at the limit of $\varepsilon \rightarrow 0$; the integral equation becomes - when $(\xi, \eta)$ is on ' $\mathrm{S}_{\mathrm{o}}$ ',

$$
\frac{1}{2} \phi+\int_{\mathrm{S}_{\mathrm{o}}}\left(\phi \frac{\partial \mathrm{g}^{*}}{\partial \mathrm{n}}\right) \mathrm{ds}=\int_{\mathrm{S}_{\mathrm{o}}} \mathrm{g} * \frac{\partial \phi}{\partial \mathrm{n}} \mathrm{ds}
$$

or

in the discrete form,

$$
\frac{1}{2} \phi_{\mathrm{s}}^{\mathrm{i}}+\sum_{\substack{\mathrm{j}=1 \\ \mathrm{j} \neq \mathrm{i}}}^{\mathrm{N}} \phi^{\mathrm{j}} \frac{\partial \mathrm{g} *(\mathrm{j}, \mathrm{i})}{\partial \mathrm{n}_{\mathrm{j}}} \mathrm{ds}_{\mathrm{j}}=\sum_{\mathrm{j}=1}^{\mathrm{N}} \mathrm{g} *(\mathrm{j}, \mathrm{i}) \frac{\partial \phi^{\mathrm{j}}}{\partial \mathrm{n}_{\mathrm{j}}} \mathrm{ds}_{\mathrm{j}} ; \quad \mathrm{i}=1, \mathrm{~N}
$$

Where, ' $\mathrm{N}$ ' is the number of facets or subdivisions along the body boundary $\mathrm{S}_{\mathrm{O}}$. Application of green's identity for all the facets would result in ' $N$ ' number of equations for the same number of unknown values of $\phi$, along $S_{\mathrm{O}}$. In Equation (14), $\phi$ can be either $\phi_{\mathrm{S}}$ or $\phi_{\mathrm{r}}$ and accordingly the derivative of $\phi$, appearing on RHS of the above equation should be replaced for $\phi_{\mathrm{S}}$ and $\phi_{\mathrm{r}}$. The resulting set of complex simultaneous equations can be solved by any standard elimination procedures to obtain the potentials. Once, the values of $\phi$ on the body surface are calculated, then through Green's Identity the potential over the whole domain can be obtained. The scattered potentials $\Phi_{s}$ as $x \rightarrow \pm \infty$ is evaluated to determine the far field reflection and transmission characteristics of the diffracted wave. Thus the total potential at $x=+\infty$ is given as 
$\Phi(x, d)=\Phi_{o}(x, d)+\int\left[\begin{array}{l}i g_{o}(d, \eta) \frac{\partial \Phi_{o}}{\partial n}(\xi, \eta) e^{i k(x-\xi)}+ \\ \Phi_{s}(\xi, \eta) k g_{o}(d, \eta) \frac{\partial \xi}{\partial n} e^{i k(x-\xi)}+\Phi_{s}(\xi, \eta) k g_{o}^{\prime}(d, \eta) \frac{\partial \eta}{\partial n} e^{i k(x-\xi)}\end{array}\right] d l$

in which $\Phi_{o}(x, d)=(g H / 2 \omega) e^{i k x}$. Normalising Eq. 15 by letting

$\bar{\Phi}(x, d)=\left(1+C_{1}\right) e^{i k x}$

Where

$C_{1}=i \int\left[g_{o}(d, \eta) \frac{\partial \bar{\Phi}_{o}}{\partial n}(\xi, \eta)+k \bar{\Phi}_{s}(\xi, \eta)\left\{-i g_{o}(d, \eta) \frac{\partial \xi}{\partial n}+g_{o}^{\prime}(d, \eta) \frac{\partial \eta}{\partial n}\right\}\right] e^{-i k \xi} d l$

where

$g_{o}^{\prime}(y, \eta)=\frac{1}{k} \frac{k^{2}-v^{2}}{k^{2} d-v^{2} d+v} \cosh (k d) \sinh k \eta$

$\mathrm{k}$ is the wave number $k=\frac{2 \pi}{L}, v=\frac{\omega^{2}}{g}, \omega=\frac{2 \pi}{T}$

Similarly at $x=-\infty$ and $\mathrm{y}=0$

$$
\begin{aligned}
& \bar{\Phi}(x, d)=e^{i k x}+C_{2} e^{-i k x} \text { where } \\
& C_{2}=i \int\left[g_{o}(d, \eta) \frac{\partial \Phi_{o}}{\partial n}(\xi, \eta)+k \bar{\Phi}_{s}(\xi, \eta)\left\{i g_{o}(d, \eta) \frac{\partial \xi}{\partial n}+g_{o}^{\prime}(d, \eta) \frac{\partial \eta}{\partial n}\right\}\right] e^{i k \xi} d l
\end{aligned}
$$

The free surface displacement is given as

$$
\eta(x, t)=\frac{1}{g} \operatorname{Re}\left\{\frac{\partial \Phi}{\partial t}(x, d, t)\right\}=\operatorname{Re}\left\{-i \Phi(x, d) e^{-i \omega t}\right\}
$$

The transmission and reflection coefficients $\left(\mathrm{K}_{\mathrm{t}}\right.$ and $\left.\mathrm{K}_{\mathrm{r}}\right)$ are given as

$$
\begin{aligned}
& K_{t}=\sqrt{\left(\left(1+\operatorname{Re}\left\{C_{1}\right\}\right)^{2}+\left(\operatorname{Im}\left\{C_{2}\right\}\right)^{2}\right)} \\
& K_{r}=\sqrt{\left(\left(\operatorname{Re}\left\{C_{1}\right\}\right)^{2}+\left(\operatorname{Im}\left\{C_{2}\right\}\right)^{2}\right)}
\end{aligned}
$$

The dynamic pressure on the surface of the structure follows from Bernoulli's equation 
$p(x, y)=\rho \operatorname{Re}\left\{\frac{\partial \Phi}{\partial t}(x, y, t)\right\}=\rho \omega \operatorname{Re}\left\{-i \Phi(x, y) e^{-i \omega t}\right\}$

Where velocity squared terms have been neglected in accordance with linear theory. The forces in horizontal and vertical directions are obtained by the integration of pressure over the surface of the structure.

$$
\begin{aligned}
& F_{x}=\int_{C}-p \frac{\partial n}{\partial x} d l \\
& F_{y}=\int_{C}-p \frac{\partial n}{\partial y} d l
\end{aligned}
$$

\section{Experimental Investigations}

Experimental studies were carried out to study the performance characteristics of Pontoon floating Breakwater in the flume facilities at the Department of Ocean Engineering, Indian Institute of Technology Madras, India. The detailed investigations carried out are reported herein. The flume characteristics are as follows:

Length: 30m; Width: 2.0m; Depth: 1.6m

Maximum water depth: 1.0m; Wave generator: Piston type

Waves generated: Monochromatic; Range of wave heights: 0.05 to $0.32 \mathrm{~m}$

Range of wave period: 0.8 to $2.5 \mathrm{~s}$; Range of wave length: 0.9984 to $6.9829 \mathrm{~m}$

Range of wave steepness parameter $\left(\mathrm{H}_{\mathrm{i}} / \mathrm{gT}^{2}\right): 0.0008$ to 0.0510

Wave absorber: Rubble mound with $94 \%$ wave energy absorption.

Table 1: Properties of floating pontoon breakwater (For Experimental Study)

\begin{tabular}{|c|c|c|c|}
\hline \hline Model property & Symbol & Unit & Value \\
\hline Length & $\mathrm{L}_{\mathrm{m}}$ & $\mathrm{m}$ & 1.96 \\
\hline Width & $\mathrm{W}$ & $\mathrm{m}$ & 0.4 \\
\hline Pontoon draft (Max) & $\mathrm{d}_{1}$ & $\mathrm{~m}$ & 0.4 \\
\hline Mooring Stiffness & $\mathrm{K}_{\mathrm{m}}$ & $\mathrm{N} / \mathrm{mm}$ & 25 \\
\hline
\end{tabular}


Table 1 summarises the rigid body properties of the model system also indicating appropriate notations. The floating breakwater system is naturally stiff against motions as the metacenter is well above the centre of gravity. In addition, the taut mooring configuration is also expected to effectively control the motions, thereby reducing the radiating waves from the structure, which could create disturbances on the sea-side as well as the lee-side.

\subsubsection{Model parameters}

A conventional dimensional analysis has been carried-out to arrive at relevant characteristic numbers for the floating breakwater model. The experimental ranges considered for the non-dimensional parameters for the present studies are summarised in Table. 2. These ranges were selected so as to enclose the field conditions.

Table 2: Non-dimensional parameters and their ranges

\begin{tabular}{||l|l|}
\hline \hline Model Parameter & Range \\
\hline \hline Wave Steepness Parameter(Hi/gT $\left.{ }^{2}\right)$ & 0.0008 to 0.0510 \\
\hline Relative Width $(\mathrm{W} / \mathrm{L})$ & $0.100-0.900$ \\
\hline Relatives Draft $(\mathrm{d} / \mathrm{h})$ & $0.20,0.4,0.6$ (Theoretical) \\
& 0.2 (Experimental) \\
\hline Relative spacing of the pontoons $\left(\mathrm{G} / \mathrm{W}_{\mathrm{p}}\right)$ & $0.5,1.0,1.5 \& 2.0$ (Theoretical) \\
& 0.5 (Experimental) \\
\hline
\end{tabular}

\subsubsection{Model Instrumentation}

Linear resistance type wave gauges of high sensitivity were used to measure the water surface elevations in the spaces between the pontoons. Ring type load cells, with strain gauges in full Wheatstone bridge were fabricated to measure in-line mooring tensions. The load cell was designed for a maximum capacity of $600 \mathrm{~N}$ with a sensitivity of $0.15 \mathrm{~N}$ respectively. These were connected to the mooring lines with shackle and hinge arrangements to facilitate transfer of only in-line tensions to the load cells.

\subsection{Model set-up}

The experimental set-up for the model dynamics testing is shown in Fig.3. The figure shows the floating breakwater model moored to anchor frames at pre-determined locations. Locations and arrangement of the wave probes, and their instrumentation scheme were also schematised in the figure. Wave probes $\left(\mathrm{H}_{1}-\mathrm{H}_{5}\right)$ were deployed to measure the wave elevations on the wave maker side, wave absorber side and in the gaps respectively. As, the wave absorber has higher efficiency in absorbing the incident wave energy, (up to $95 \%$ of energy) it was assumed that there were negligible reflections from the beach.

Dynamic tensions were measured in four mooring lines $\left(\mathrm{M}_{1}-\mathrm{M}_{4}\right)$, two on the wave maker side and two on the absorber side. Wave maker side mooring forces were expected to be larger than the absorber side forces and are critical for design purpose. At the beginning of each and every test run the load cells were checked and corrected for equal initial tensions, if needed.

This experimental set-up was maintained throughout the tests. All the transducers were calibrated frequently and checked for linearity. Initial readings of all the transducers were balanced and recorded before the start of each and every test run. These average initial conditions were subtracted from the recorded quantities to get absolute dynamic quantities. Data from all the transducers were collected and stored into a PC through an amplifier and a filter. 

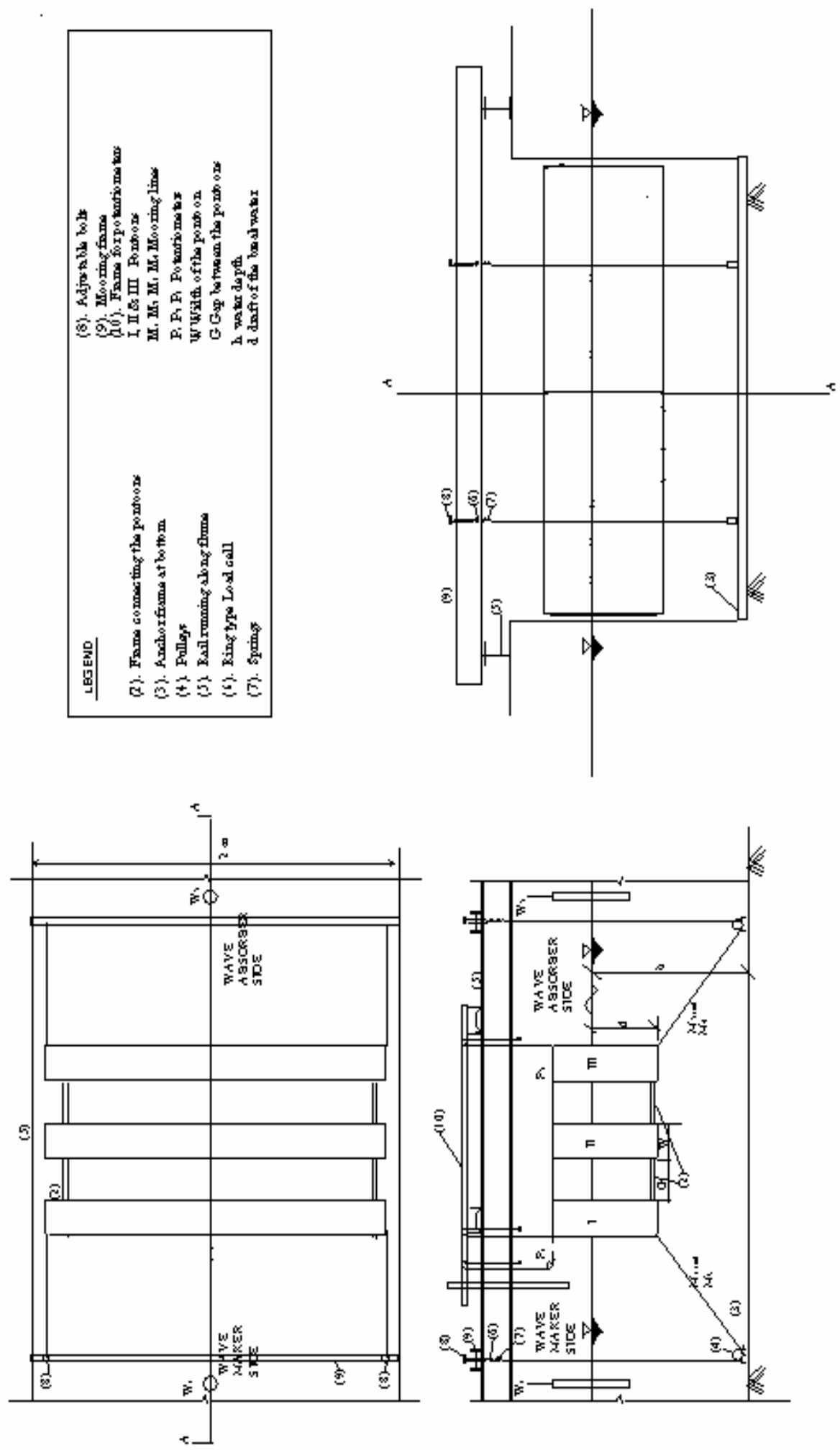

吾

\subsection{Analysis of data and presentation of results}

Data collected, with a sampling frequency of $20 \mathrm{~Hz}$, were processed to get relevant physical quantities. The procedures for analysis of the analog raw data are discussed in this section.

Customised MATLAB ${ }^{\odot}$ codes were developed to convert the analog data into physical data, using the calibration factors of each transducers. Data from wave probes and load cells were directly converted 
using the factors to get the amplitudes of incident, reflected and transmitted waves; mooring forces in generator and absorber side mooring lines.

For presentation of the results, the wave amplitudes on the lee side, generator side and at the model were normalised with the incident wave amplitude $\left(\mathrm{H}_{\mathrm{i}} / 2\right)$, to yield the transmission $\left(\mathrm{K}_{\mathrm{t}}\right)$ and reflection $\left(\mathrm{K}_{\mathrm{r}}\right)$ coefficients and relative water surface elevations $\left(\mathrm{H} / \mathrm{H}_{\mathrm{i}}\right)$ inside the gap respectively. To normalise the amplitude of dynamic mooring forces, the total pressure force exerted by a progressive wave on a vertical wall of unit width, given by $\left[\mathrm{H}_{\mathrm{i}} \rho \operatorname{\rho tanh}(\mathrm{kh}) /(2 \mathrm{k})\right]$, is used and the above results presented against W/L. The W/L value, known as 'relative width', is an important parameter in studying the performance of any floating body and its dynamic behaviour, because, the $\mathrm{W} / \mathrm{L}$ is purely frequency dependent.

\section{Results and Discussions:}

\subsection{An overview of the work}

A parametric study was carried out to investigate the sensitivity of the breakwater performance to the various wave and structural parameters. In numerical results presented herein, the body boundary was divided into more than 300 line segments in order to ensure that the numerical convergence is achieved. The auxiliary boundaries at $x= \pm x_{\infty}$ were placed three to four water depths away from the structure, sufficiently far to ensure that the evanescent wave modes could be neglected (Dean and Darymple,1984).

The performance of pontoon floating breakwater depends upon factors such as width of the float, interspacing, draft, mooring system and mooring line stiffness. In the present study the width of individual pontoon is kept constant and the total width of the float is varied by varying the interspaces $(\mathrm{G})$ and draft (d).

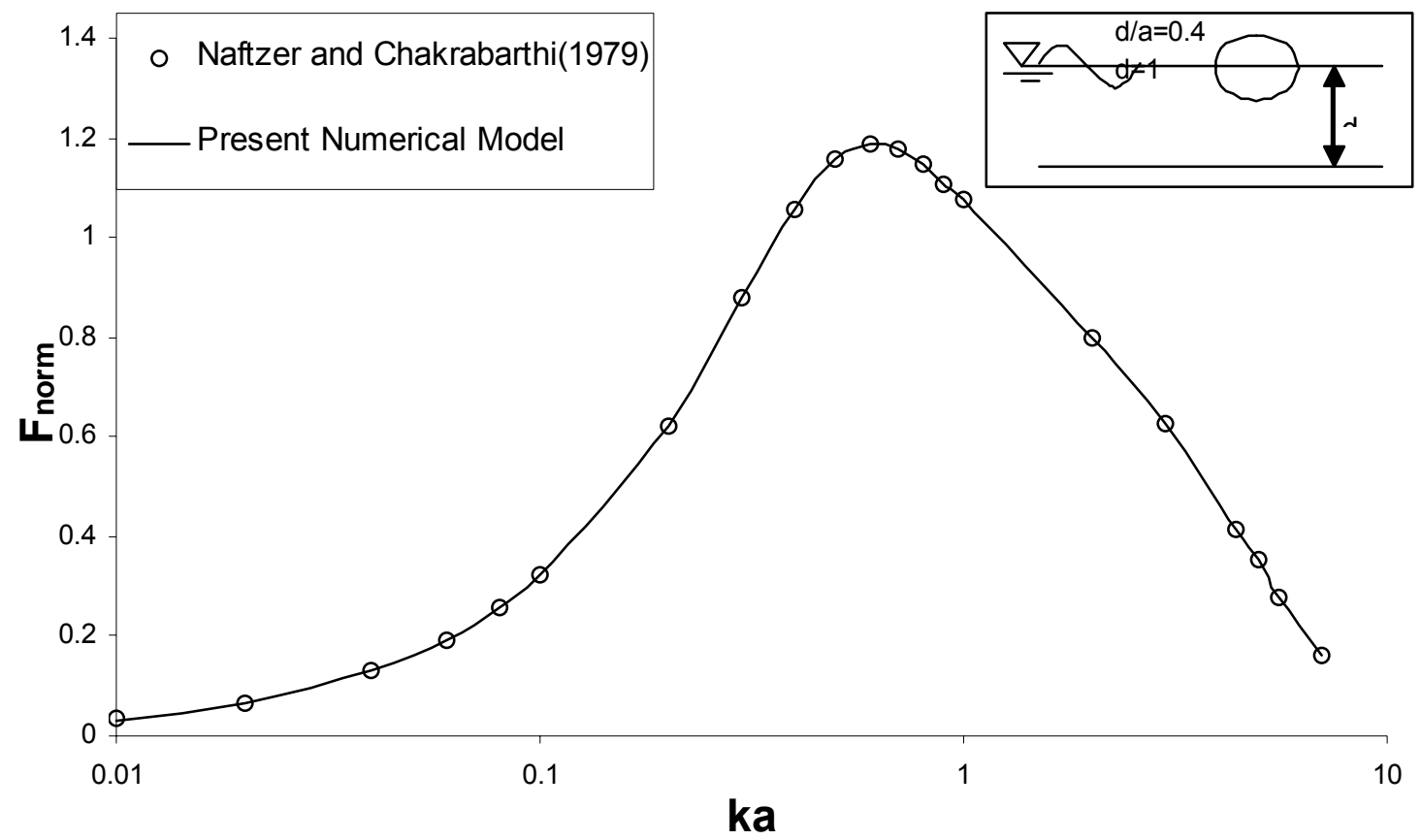

Fig. 4: Validation of present Numerical model with that of Naftzer and Chakrabarthi (1979) 


\subsection{Validation of numerical model}

The present numerical model is validated with the numerical model of Naftzer and Chakrabarthi (1979). Fig. 4 shows the comparison of results thus validating the numerical model.

Table 3: Performance comparison of floating breakwaters

\begin{tabular}{|c|c|c|c|c||}
\hline Configuration & $\mathbf{d} / \mathbf{h}$ & $\mathbf{W} / \mathbf{L}$ & $\mathbf{K}_{\mathbf{t}}$ & Reference \\
\hline $\begin{array}{c}\text { Double pontoon } \\
\text { floating breakwater }\end{array}$ & 0.78 & $>0.6$ & 0.50 & Brebner and Ofoya (1968) \\
\hline $\begin{array}{c}\text { Floating tire } \\
\text { breakwater }\end{array}$ & $0.16-0.32$ & $>1.2$ & 0.5 & Bishop(1982) \\
\hline $\begin{array}{c}\text { Sloping float } \\
\text { breakwater }\end{array}$ & 0.27 & $>0.58$ & 0.50 & Carver and Davison(1983) \\
\hline $\begin{array}{c}\text { Dual pontoon } \\
\text { floating breakwater }\end{array}$ & 0.2 & $>0.65$ & 0.5 & Williams and Abul Azm(1997) \\
\hline $\begin{array}{c}\text { Interconnected } \\
\text { multiple floating } \\
\text { pontoons }\end{array}$ & 0.2 & $>0.60$ & 0.5 & Present \\
\hline
\end{tabular}

\subsection{Performance comparison of floating breakwaters:}

Table 3 shows the comparison of performance of different types of floating breakwater in terms of their ability in controlling the transmission coefficient $\left(\mathrm{K}_{\mathrm{t}}\right)$. Though different types of floating breakwater are referred in Table 3 , for which $\mathrm{W} / \mathrm{L}$ and $\mathrm{d} / \mathrm{h}$ ratios control $\mathrm{K}_{\mathrm{t}}$. The above parameters were considered as reference for comparison. From the table it is inferred that depending on the configuration of the floating breakwater $\mathrm{W} / \mathrm{L}$ ranges between 0.6 and 1.2, and $\mathrm{d} / \mathrm{h}$ between 0.2 and 0.78 to restrict $\mathrm{K}_{\mathrm{t}}$ to 0.5 . In case of dual pontoon floating breakwater (Williams and Abul Azm(1997)) $0.2<\mathrm{K}_{\mathrm{t}}<0.5$ is achieved for $0.65<\mathrm{W} / \mathrm{L}<1$ and $\mathrm{d} / \mathrm{h}=0.2$, whereas in the present case $\mathrm{K}_{\mathrm{t}}$ is further restricted $0.1<\mathrm{K}_{\mathrm{t}}<0.5$ for $0.6<\mathrm{W} / \mathrm{L}<0.85$, a definite advantage of present configuration of floating breakwater.

\subsection{Effect of $G / W_{p}$ on transmission coefficient:}

The variation of the transmission coefficient for a range of $\mathrm{G} / \mathrm{Wp}$ (from 0.5 to 2.0 in the intervals of 0.5 ) has been investigated for $\mathrm{d} / \mathrm{h}=0.2$. With the draft fixed as $\mathrm{d} / \mathrm{h}=0.2$, for varying $\mathrm{G} / \mathrm{W}_{\mathrm{p}}$, the system was analysed for its response to different wave frequencies (W/L=0.1 to 0.9 ) and the fig. 5 depicts the trend. It is inferred that as the gap between the pontoons increases from $\mathrm{G} / \mathrm{W}_{\mathrm{p}}=0.5$ to $\mathrm{G} / \mathrm{W}_{\mathrm{p}}=2.0$ the $\mathrm{K}_{\mathrm{t}}$ increases by $33 \%$ for $\mathrm{W} / \mathrm{L}=0.15$ to $\mathrm{W} / \mathrm{L}=0.5$ but a notable feature is that the effect of higher $\mathrm{G} / \mathrm{W}_{\mathrm{p}}$ is minimal in the above mentioned range. As $\mathrm{W} / \mathrm{L}$ increases from 0.5 to 0.9 the effect of $\mathrm{G} / \mathrm{W}_{\mathrm{p}}$ is dominant as a lower $\mathrm{G} / \mathrm{Wp}$ provides an appreciable reduction in transmission of incident wave. Minor deviation (5\%-15\%) between observed and theoretical results is due to the fact that the mooring stiffness could not be simulated precisely in the laboratory. In the development of the theory taut moored condition for the floating body was considered to enable assessment of the performance of the floating breakwater with the assumptions that its motions are satisfied.

As $\mathrm{G} / \mathrm{W}_{\mathrm{p}}=0.5$ and $\mathrm{d} / \mathrm{h}=0.2$ in restricting $\mathrm{K}_{\mathrm{t}}$ below 0.5 the above configuration is further investigated.

The reflection coefficients for the present configuration (Fig.6) increases by $50 \%$ for an increase of $\mathrm{W} / \mathrm{L}$ from 0.15 to 0.45 . The plot shows there is good agreement between he values obtained experimentally and those predicted theoretically. 


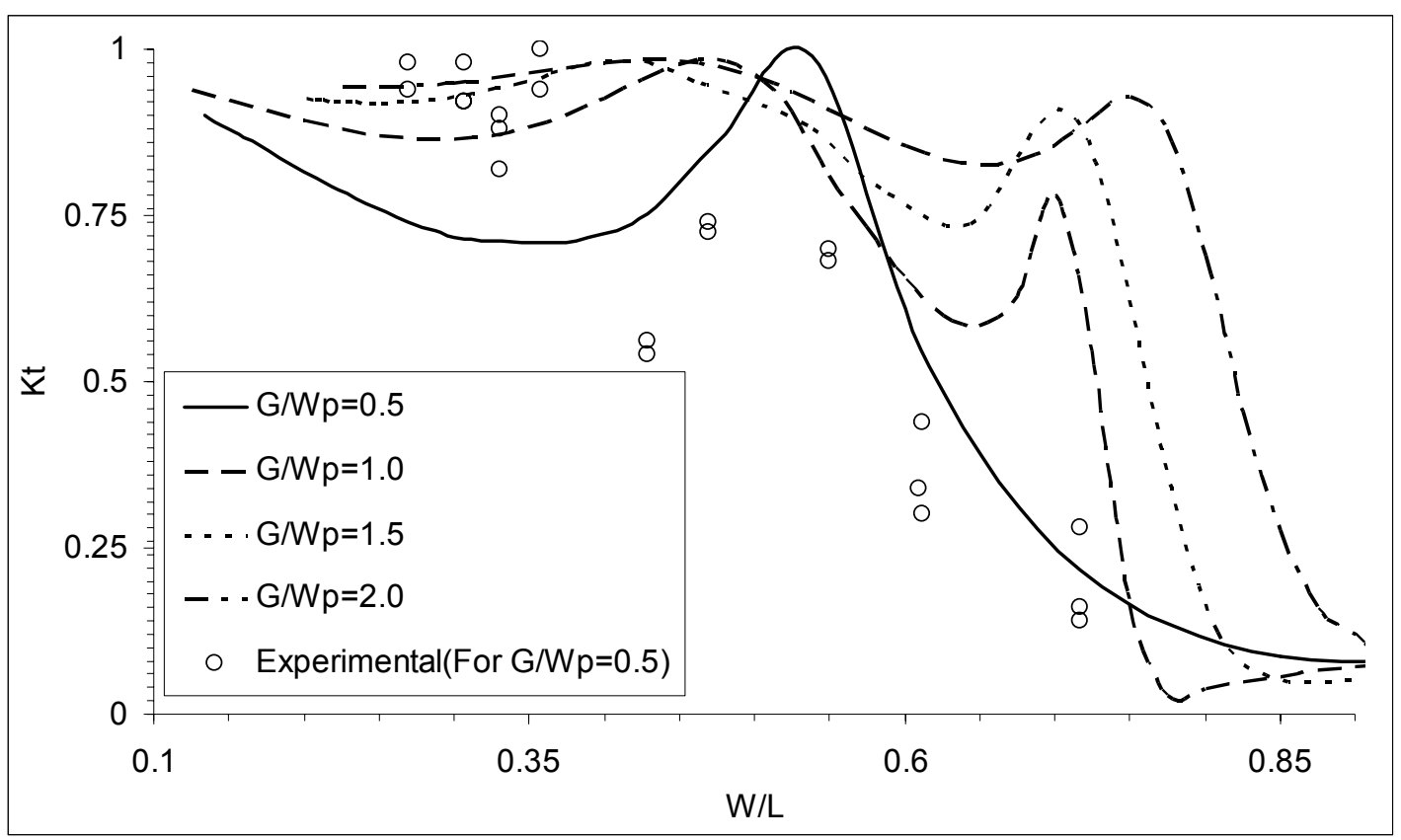

Fig. 5: Variation of Transmission coefficient of Triple pontoon floating breakwater with varying $\mathrm{W} / \mathrm{L}$. for different $\mathrm{G} / \mathrm{W}_{\mathrm{p}}$ the draft being constant $(\mathrm{d} / \mathrm{h}=0.2)$

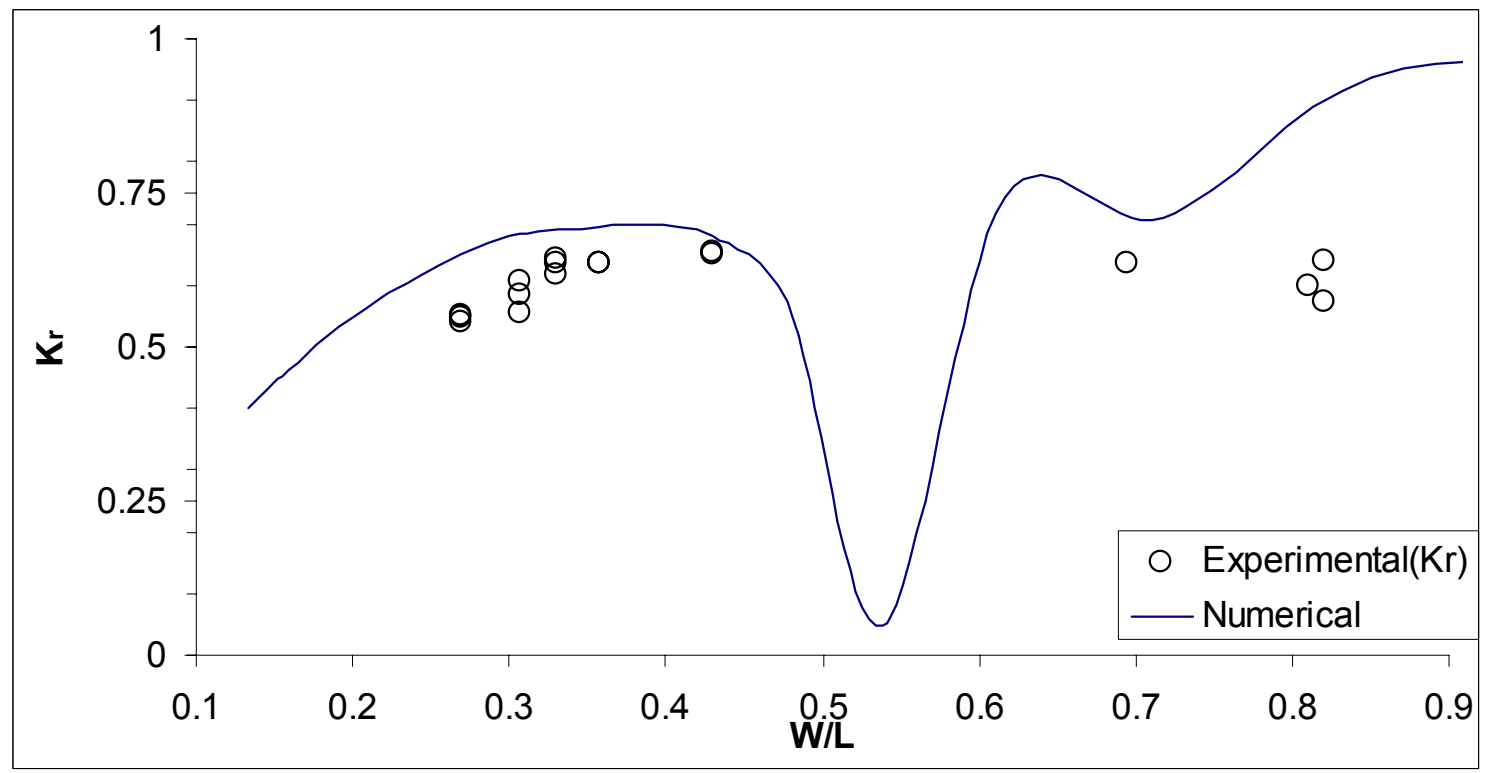

Fig. 6: Variation of Reflection coefficient of Triple pontoon floating breakwater with varying $\mathrm{W} / \mathrm{L}$. for different $\mathrm{G} / \mathrm{W}_{\mathrm{p}}$ the draft being constant $(\mathrm{d} / \mathrm{h}=0.2)$

\subsection{Forces:}

The force experienced by the floating breakwater in the wave direction is plotted against $\mathrm{W} / \mathrm{L}$ (Fig.7). From the figure 7 it is inferred that for short waves $(0.5<\mathrm{W} / \mathrm{L}<1)$ the force ranges from 0.18 to 0.2 and for long waves $(0.1<\mathrm{W} / \mathrm{L}<0.5)$ the force ranges from 0.1 to 0.2 . Since the mooring stiffness is not exactly reproduced in the laboratory there is a variation (nearly $50 \%$ ) in the values predicted theoretically and those obtained experimentally. Results of physical model tests for $\mathrm{G} / \mathrm{W}_{\mathrm{p}}=0.5$ and $\mathrm{d} / \mathrm{h}=0.2$ are found lower than that of theoretically predicted values due to the taut moored condition. 


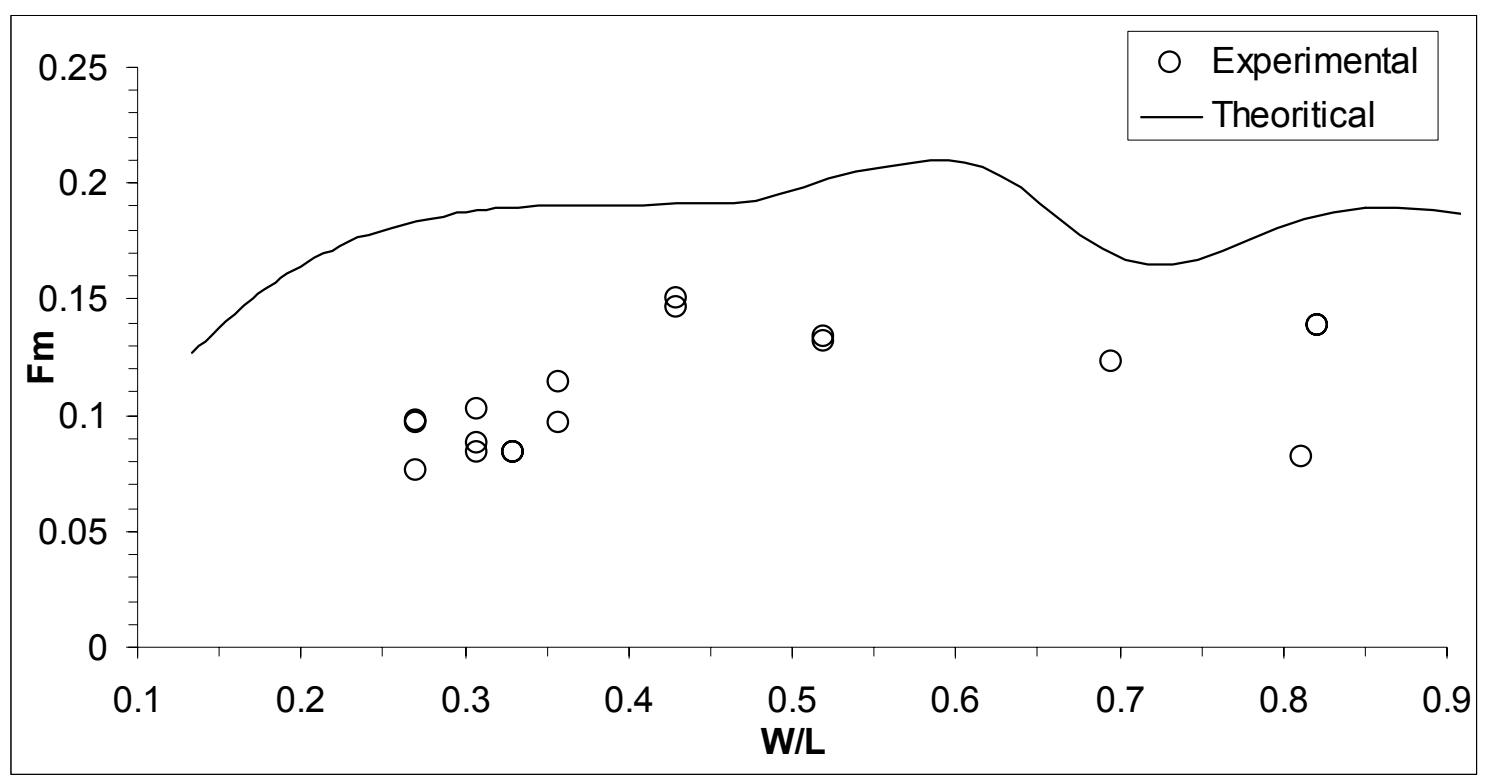

Fig. 7: Non dimensionalized mooring forces on the wave maker side of the Pontoon floating breakwater for a draft of $\mathrm{d} / \mathrm{h}=0.2$ and $\mathrm{G} / \mathrm{W}_{\mathrm{p}}=0.5$.

The forces in the lee side mooring lines (Fig. 8) depict an increasing trend from 0.05 at $\mathrm{W} / \mathrm{L}=0.2$ to 0.1 at $\mathrm{W} / \mathrm{L}=0.5$ and further increase with $\mathrm{W} / \mathrm{L}$ from 0.5 to $\mathrm{W} / \mathrm{L}=0.9$. The reason is higher transmission ratio at these $\mathrm{W} / \mathrm{L}$ value resulting in a substantial orbital motion of water particles at the lee side imparting a larger pull in the lines.

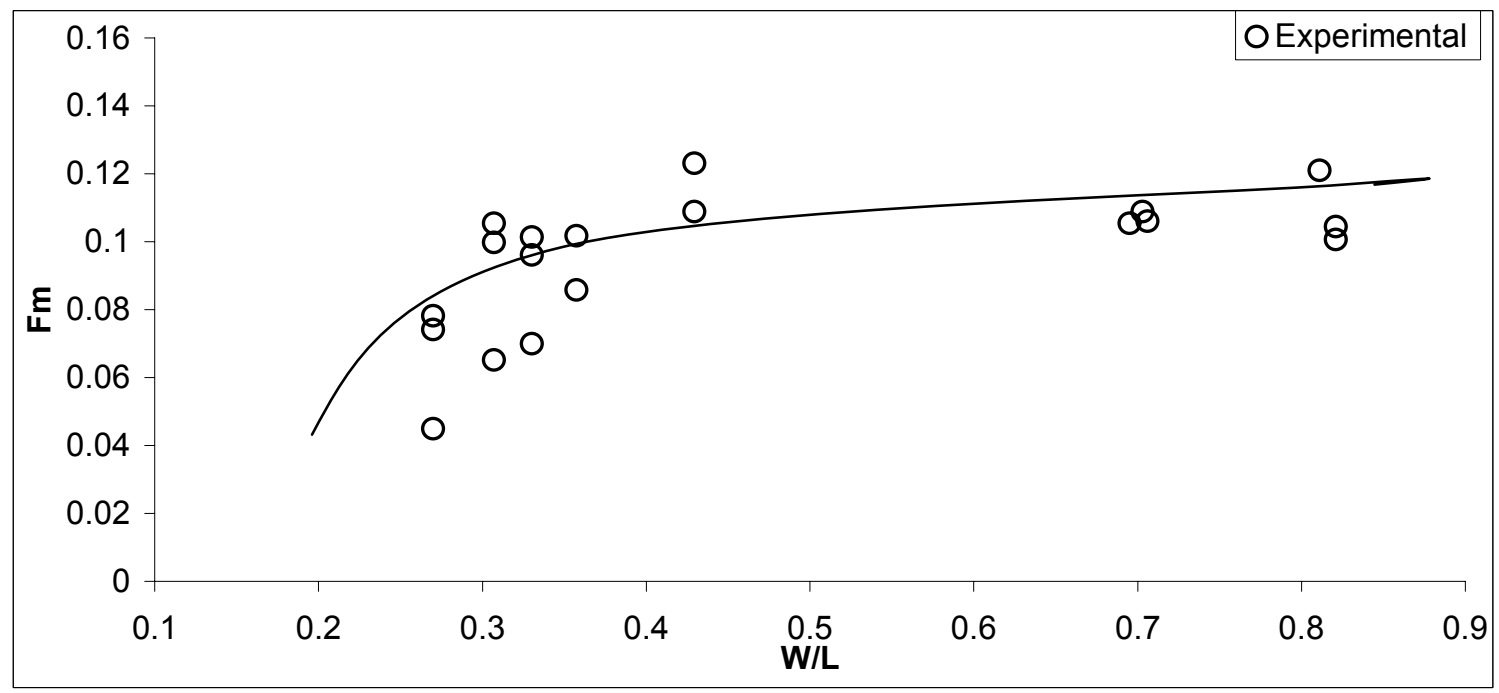

Fig. 8: Non dimensionalised mooring line forces on the absorber side of the pontoon floating breakwater for a draft of $\mathrm{d} / \mathrm{h}=0.2$ and $\mathrm{G} / \mathrm{W}_{\mathrm{p}}=0.5$.

\subsection{Water surface oscillations:}

The water surface oscillations in between the pontoons indicate the disturbance that take place when a wave moves through the floating system. Fig. 9 shows the normalised water surface oscillations $\left(\mathrm{H} / \mathrm{H}_{\mathrm{i}}\right)$ inside the interspace of the floating breakwater. The trend in the experimental results closely follows the numerically predicted values. Large water surface oscillations in the interspaces cause propagation of disturbance on the lee side of the floating breakwaterleading to 
increase in wave transmission The normalised amplitudes of water surface oscillations attains a maximum value of about 3.0 at $\mathrm{W} / \mathrm{L}=0.5$.

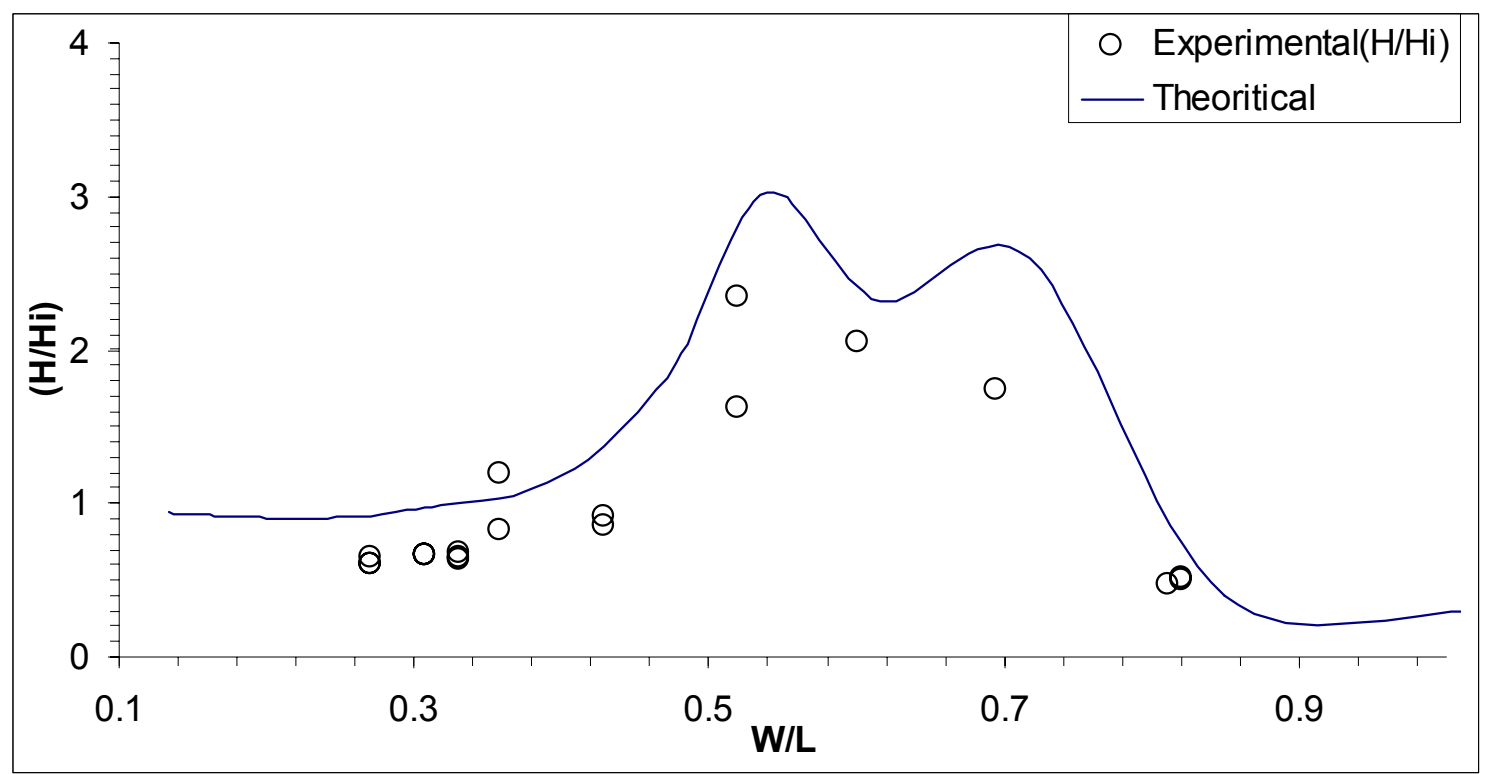

Fig. 9: Non-dimensionalized water particle oscillations in the gap between the pontoon of floating breakwater for a draft of $\mathrm{d} / \mathrm{h}=0.2$ and $\mathrm{G} / \mathrm{W}_{\mathrm{p}}=0.5$.

\section{Conclusions:}

1. The present configuration is effective in obstructing waves at lower draft

2. This configuration attempts in increasing width of floating breakwater without increasing the material by providing spacing between the pontoons so that the spaces act as damping chambers.

3. For a varying $\mathrm{G} / \mathrm{W}_{\mathrm{p}}$ different parameters' variation is studied and it is found that $\mathrm{G} / \mathrm{W}_{\mathrm{p}}=0.5$ gives an optimum bandwidth of frequencies for floating breakwater operation.

4. The transmission coefficient $0.95<\mathrm{K}_{\mathrm{t}}<0.1$ for $0.1<\mathrm{W} / \mathrm{L}<0.85$ and $\mathrm{d} / \mathrm{h}=0.2$.

5. The forces in the mooring lines $0.6<\mathrm{Fm}<0.15$ for $0.1<\mathrm{W} / \mathrm{L}<0.85$ and $\mathrm{d} / \mathrm{h}=0.2$ were obtained experimentally.

6. The water surface oscillations in the interspaces ranges from $0.3<\mathrm{H} / \mathrm{H}_{\mathrm{i}}<3$ for $0.1<\mathrm{W} / \mathrm{L}<0.9$ for a $\mathrm{d} / \mathrm{h}=0.2$.

\section{Practical Relevance:}

The three pontoons separated by mutual gaps and rigidly connected by a deck can be used as dock as well as floating breakwater. The design of floating breakwater should ensure careful selection of interspaces such that the wave transmission is effectively controlled and water surface oscillations in the interspaces are minimum. 


\section{Acknowledgements:}

The authors express their deep sense of gratitude to the authorities of Indian Institute of Technology Madras for providing necessary help needed for the present work.

\section{References}

Abul-Azm, A.G. and Gesraha, M.R. (2000): Approximation to the Hydrodynamics of Floating Pontoons Under Oblique Waves, Ocean Engineering 27,365-384.

Bishop,C.T. (1982): Floating Tire Breakwater Design and Comparison, Journal of waterway, Port, Coastal and Ocean Engineering, ASCE, 103(3),421-426.

Brebner,A. and Ofuya,A.O. (1968): Floating Breakwaters, Proceedings of he $11^{\text {th }}$ Conference on Coastal Engineering, ASCE,2,1055-1094.

Carver,R.D. and Davison,D.D. (1983): Sloping Float Breakwater Model Study, Coastal Structures, $83,417-432$.

Bretz,G (1988): Deploymentof Deployable Ports May Prove Vital for U. S. Navy, Offshore, 48(12),1418.

Dean,R.G., Dalrymple,R.A.,(1984): Water Wave Mechanics for Scientists and Engineers. PrenticeHall, Eaglewood Cliffs, New Jersey.

Drimer, N, Agon, Y and Stiassnie, M, (1992): A Simplified Analytical Model for a Floating Breakwater in Water of Finite Depth, Applied Ocean Research, Vol.14, pp33-41.

Drobyshevski, Y.,(2004): Hydrodynamic Coefficients of Two Dimensional, Truncated Rectangular Floating Structure in Shallow Water, Ocean Engineering, Vol.31, pp 305-341.

Fang, M. C. and Kim,C.H.(1986): Two -Dimensional Analysis on the Lateral Drifting Force Between Two Floating Structures, Vol. 30, 194-200.

Harris,A.J., and Thomas,J.M. (1974): The Harris Floating Breakwater, Proc. Floating breakwater Conf. Newport, R.I ,pp 213-232.

Joly,,J. (1905): On floating Breakwaters, Royal Dublin Society, Scientific Proceedings,Vol.10,pt. 3, pp.378-344.

Kowalski, T. (1974): 1974-Floating Breakwater Conference Papers, Marine Technical Report Series Number 24, University of Rhode Island, Kingston.

Liang, N.K, Huang, J.S., and Li, C.F., (2004): A Study of Spar Buoy Floating Breakwater, Ocean Engineering. Vol.31. pp 43-60.

Naftzer,R..A., and Chakrabarthi,S.K. (1979): Scattering Of Waves By Two Dimensional Circular Obstacles In Finite Water Depths, Journal of Ship Research, 23.

Perunovic, J.V. and Jensen, J.J., (2003): Wave Loads On Ships Sailing In Restricted Water Depth, Marine Structures, Vol.16, pp 469-485.

Richey, E.P., and Nece, R.E.(1974): Floating Breakwater- State of the Art, Proc. Floating Breakwater Conf., Newport, R.I., 1-20.

Shashikala, A.P., Sundaravadivelu, R, and Ganpathy, C, (1997): Dynamics of a Moored Barge under Regular and Random Waves, Ocean Engineering, Vol.24, No. 5, pp-401-430.

Valioilis, I.A. (1989): Motion Response And Wave Attenuation Of Linked Floating Breakwaters, J.Waterway, Port, Coastal and Ocean Engineering, Vol.116, No. 5,pp 558-574.

WanHausen, J.V and Laitone, E.V. (1960): Surface Waves, In Handbuch der Physic, ed. Flugge.S.Springer-Verlag, Berlin, ix, 446-778.

Williams, A.N. and Abul-Azm, A.G. (1997): Dual Pontoon Floating Breakwater, Ocean Engineering, Vol.24, No.5, pp-465-478.

Williams, A.N. and Abul-Azm, A.G.,(2000): Floating Pontoon Breakwater, Ocean Engineering, Vol.27, pp-221-240. 